\title{
Health-Related Quality of Life in Patients with a History of Myocardial Infarction and Stroke
}

\author{
Jan-Philipp Bach ${ }^{a} \quad$ Oliver Riedel $^{b} \quad$ Lars Pieper $^{b} \quad$ Jens Klotsche $^{b} \quad$ Richard Dodel $^{a}$ \\ Hans-Ulrich Wittchen ${ }^{b}$ \\ ${ }^{a}$ Department of Neurology, Philipps-University Marburg, Marburg, and ${ }^{b}$ Institute of Clinical Psychology and \\ Psychotherapy, Technische Universität Dresden, Dresden, Germany
}

\section{Key Words}

Health-related quality of life - Stroke $\cdot$ Myocardial infarction • DETECT study

\begin{abstract}
Background: There is a lack of the generic data comparing the influence of different diseases on health-related quality of life ( $\mathrm{HrQoL}$ ) in a representative sample of primary care patients. Methods: Patient data were collected in the DETECT (Diabetes Cardiovascular Risk Evaluation: Targets and Essential Data for Commitment of Treatment) study including 55,000 patients. Results: 3,109 patients (33.3\% female) with myocardial infarction (MI), stroke or both were compared to patients with a wide range of other diagnoses. Stroke and MI patients revealed a lower HrQoL as compared to patients with other diagnoses. Stroke was associated with strongest quality of life reduction. Multivariate analysis revealed several different determining factors. Conclusions: The reduction of HrQoL of patients with Ml and stroke is primarily determined by the CNS insult. These data provide further evidence that early diagnosis and treatment of cardiovascular risk factors is essential to reduce subsequent stroke.
\end{abstract}

Copyright $\odot 2010$ S. Karger AG, Basel

\section{Introduction}

Both stroke and myocardial infarction (MI) are among the leading causes of long-term disability and mortality in Western Europe. Similar risk factors have been described for both diseases. Arterial hypertension, dyslipidemia, diabetes mellitus, smoking habits, obesity, depression and family history have all been identified as significant risk factors for the development of cardiovascular disease and stroke $[1,2]$.

Stroke is associated with a moderate mortality rate. Most patients usually survive their first ischemic stroke, but data demonstrate that many of these patients are severely impaired suffering from disability [3]. Thus, stroke

Members of the DETECT-Study group include: Principal investigator: Professor Dr. H.-U. Wittchen; Staff members: Dipl.-Psych. L. Pieper, Dipl.-Math. J. Klotsche, Dr. T. Eichler, Dr. H. Glaesmer, E. Katze. Steering Committee: Professor Dr. H. Lehnert (Lübeck), Professor Dr. G.K. Stalla (München), Professor Dr. A. M. Zeiher (Frankfurt); Advisory Board: Professor Dr. W. März (Heidelberg/Graz), Professor Dr. S. Silber (München), Professor Dr. Dr. U. Koch (Hamburg), Priv.-Doz. Dr. D. Pittrow (München/Dresden), Professor Dr. M. Wehling (Mannheim), Dr. D. Leistner (Frankfurt), Dr. H.J. Schneider (München), Dr. C. Sievers (München).

\section{KARGER}

Fax +41613061234 E-Mail karger@karger.ch www.karger.com
Richard Dodel, MD

Department of Neurology, Philipps University Marburg

Rudolf-Bultmann-Strasse 8

DE-35039 Marburg (Germany)

Tel. +49 6421586 6251, Fax +49 6421586 5474, E-Mail dodel@ med.uni-marburg.de 
is a leading cause of long-term disability in the USA and Europe [4]. According to data from the WHO, the stroke burden is predicted to increase from 38 million disability-adjusted life years in 1990 to 61 million in 2020 .

MI is part of a disease group termed coronary heart disease that also includes unstable angina pectoris, sudden death and MI [5]. Coronary heart disease is the leading cause of death in adults in the USA, accounting for about one third of all deaths in subjects over the age of 35 years [4]. In Germany, MI was the leading cause of death in 2004.

Furthermore, the longterm course and outcome of both, MI and stroke, is frequently associated with increased rates of depression, anxiety and social isolation, known to reduce, among other factors, the quality of life in these patients $[6,7]$.

In recent years, the introduction of quality of life questionnaires has led to an improved understanding of patient-reported health outcomes in clinical studies. Both diseases influence patients in many different ways. This multidimensional influence has not been well evaluated by standard clinical outcome measures. In this study, the EuroQol questionnaire EQ-5D [8] was used. The EuroQol questionnaire is an instrument used to describe and evaluate health states. It is a standardized instrument which provides a simple descriptive health profile with the dimensions mobility, self-care, usual activities, pain/ discomfort and anxiety/depression.

Since both diseases are associated with similar risk factors, questions have arisen as to whether there is a difference in patient-related quality of life after such an event. Therefore, we analyzed data from a large epidemiological study (DETECT, Diabetes Cardiovascular Risk-Evaluation: Targets and Essential Data for Commitment of Treatment; www.detect-studie.de) that drew upon more than 55,000 patients from the German primary care system. There were 3,109 patients with stroke, MI or both and vascular risk factors, and their influence on health-related quality of life (HrQoL) was evaluated in subgroups of patients based on whether they had experienced either MI or stroke or both.

\section{Material and Methods}

\section{Study Design}

The DETECT study is an epidemiological study in 3 stages conducted in the German primary care system. Initially, in 2003, a primary care provider survey was performed. The second stage of the study consisted of a cross-sectional point prevalence study of unselected consecutive patients who sought care in these set- tings. Patient sampling was performed on a target half day (in September 2003). Patients were informed by posters and leaflets about the possibility of study participation. All patients had to provide informed consent before participation. They were then asked to complete a self-report patient questionnaire. In addition, a structured doctor's interview and a thorough physical examination were performed. Blood samples were also drawn and analyzed in a random subset of patients. The third phase of the study consisted of 2 follow-up examinations (after 1 and 5 years) of those patients randomly assigned to laboratory workup. The follow-up visits were similar in setup to the initial visit. The DETECT study was approved by the ethical committee of the TU Dresden (AZ: EK149092003; Date: September 16, 2003). The design and sampling of the original study have been described in greater detail [9-11]. For more information see also the website (http:// www.detect-studie.de).

On the study target day, a total of 59,403 eligible patients were present in 3,188 participating primary care offices. Of these, 3,607 patients refused participation and for 278 patients, a physician's appraisal was not available. Thus, the present paper is based on data from 55,518 patients (response rate: 93.5\%) from the crosssectional part of the DETECT study. We analyzed HrQoL in the group of patients without MI or stroke, in those with either of the diseases alone as well as in patients with both diseases.

Together with clinicians we selected a set of certain risk parameters that may have an influence on the risk of stroke or MI. These included arterial hypertension, diabetes, dyslipidemia, atrial fibrillation, carotid artery stenosis, smoking habits and body mass index (BMI) and were obtained using standard measurements. In addition, the Depression Screening Questionnaire [12] was used to evaluate the presence of lifetime, current and former depression.

\section{Health-Related Quality of Life}

HrQoL was evaluated using the generic instrument EQ-5D [8]. Applicable to a wide range of health conditions and treatments, the EQ-5D not only generates a health profile but is also capable of expressing HrQoL as a single index value (utility value). Therefore, it can be used for both clinical and economic evaluations of health care. It includes a descriptive system with 5 dimensions and a visual analogue scale (EQ VAS). The 5 dimensions are mobility, self-care, usual activities, pain/discomfort and anxiety/depression. All dimensions are subdivided into 3 levels. These response levels indicate different categories: no problems, some/ moderate problems and extreme problems. In calculating the responses, there exist $243\left(3^{5}=243\right)$ possible different health states. The EQ-5D summary score was calculated according to the corresponding scoring algorithms for the German population established by Greiner et al. [13].

Data Entry and Statistical Analysis

Data were analyzed using Stata 10.0 (StataCorp [14]). Results are presented as means (SD) or number of cases (percentages) as appropriate. Group comparisons of the EQ-5D score were estimated using a linear regression framework. The assessment of independent predictors of HrQoL was performed using multivariate regression analysis with forward selection. The variables used in univariate and multivariate analyses were specified based on the opinions of a consensus among 3 specialists and data from previous studies. Variables were screened by means of the Spear- 
Table 1. Characteristics of the study population

\begin{tabular}{|c|c|c|c|c|c|}
\hline & Total & $\begin{array}{l}\text { Neither stroke } \\
\text { nor MI }\end{array}$ & MI & Stroke & MI and stroke \\
\hline Total number & $55,518(100.0)$ & $52,409(94.4)$ & $2,181(3.9)$ & $783(1.4)$ & $145(0.3)$ \\
\hline Age, years & $53.9 \pm 17.3$ & $53.0 \pm 17.3$ & $67.4 \pm 10.2$ & $68.3 \pm 10.8$ & $70.3 \pm 8.4$ \\
\hline Female gender & $32,839(59.2)$ & $31,810(60.7)$ & $640(29.5)$ & $352(44.0)$ & $37(25.9)$ \\
\hline \multicolumn{6}{|l|}{ Smoking status } \\
\hline Never smoked & $28,282(53.3)$ & $27,010(54.0)$ & $831(40.1)$ & $386(51.8)$ & $55(37.7)$ \\
\hline Former smoker & $10,812(20.6)$ & $9,539(19.2)$ & $962(45.8)$ & $250(34.1)$ & $61(43.9)$ \\
\hline Current smoker & $13,504(26.1)$ & $13,086(26.8)$ & $288(14.2)$ & $106(14.1)$ & $24(18.5)$ \\
\hline \multicolumn{6}{|l|}{ Pack years (current smokers) } \\
\hline $1-19$ & $8,116(60.8)$ & $7,856(60.7)$ & $180(65.1)$ & $64(59.1)$ & $16(74.2)$ \\
\hline $20-39$ & $4,732(36.6)$ & $4,598(36.7)$ & $91(32.5)$ & $36(38.0)$ & $7(25.8)$ \\
\hline $40-59$ & $310(2.4)$ & $302(2.4)$ & $5(2.0)$ & $3(2.9)$ & $0(0.0)$ \\
\hline $60-79$ & $29(0.2)$ & $29(0.2)$ & $0(0.0)$ & $0(0.0)$ & $0(0.0)$ \\
\hline BMI & $26.9 \pm 5.3$ & $26.8 \pm 5.3$ & $28.1 \pm 4.5$ & $27.9 \pm 5.1$ & $28.4 \pm 4.1$ \\
\hline Diabetes mellitus ${ }^{1}$ & $8,465(14.7)$ & $7,338(13.5)$ & $765(34.4)$ & $284(34.9)$ & $78(49.8)$ \\
\hline Hypertension $^{2}$ & $31,635(56.4)$ & $28,699(54.1)$ & $2,089(95.4)$ & $707(90.1)$ & $140(95.3)$ \\
\hline Hyperlipidemia & $16,178(29.5)$ & $14,211(27.5)$ & $1,436(66.3)$ & $428(54.7)$ & $103(70.3)$ \\
\hline Atrial fibrillation & $1,860(3.4)$ & $1,504(2.9)$ & $218(10.2)$ & $113(14.9)$ & $25(17.4)$ \\
\hline Carotid artery stenosis & $801(1.4)$ & $503(1.0)$ & $153(6.8)$ & $116(15.1)$ & $29(17.8)$ \\
\hline Anxiety & $3,082(5.6)$ & $2,882(5.6)$ & $128(6.2)$ & $61(8.0)$ & $11(8.8)$ \\
\hline \multicolumn{6}{|l|}{ Depression } \\
\hline Lifetime depression & $10,424(20.7)$ & $9,590(20.2)$ & $537(28.0)$ & $242(35.3)$ & $55(48.0)$ \\
\hline Current depression & $7,759(15.5)$ & $7,134(15.1)$ & $406(21.5)$ & $178(26.0)$ & $41(36.2)$ \\
\hline Former depression & $2,665(5.2)$ & $2,456(5.1)$ & $131(6.6)$ & $64(9.3)$ & $14(11.8)$ \\
\hline Sexual dysfunction & $1,285(2.4)$ & $1,062(2.1)$ & $153(7.2)$ & $52(6.8)$ & $18(12.4)$ \\
\hline Mental disability days (yes) ${ }^{3}$ & $3,061(6.6)$ & $2,825(6.4)$ & $147(8.9)$ & $71(13.5)$ & $18(20.5)$ \\
\hline Mental disability days, days & $0.7 \pm 3.5$ & $0.7 \pm 3.4$ & $1.1 \pm 4.5$ & $1.6 \pm 5.4$ & $2.2 \pm 6.4$ \\
\hline Physical disability days (yes) ${ }^{3}$ & $10,972(23.6)$ & $10,326(23.4)$ & $463(27.9)$ & $148(27.2)$ & $35(38.0)$ \\
\hline Physical disability days, days & $2.2 \pm 5.7$ & $2.1 \pm 5.6$ & $3.2 \pm 7.2$ & $3.4 \pm 7.5$ & $4.8 \pm 8.8$ \\
\hline \multicolumn{6}{|c|}{$\begin{array}{l}\begin{array}{l}\text { Values denote numbers with percentages weighted for attri- } \\
\text { tion and nonresponse in parentheses, or means } \pm \text { SD. Valid ob- }\end{array} \quad \begin{array}{c}{ }^{1} \text { Clinicians rating 'definite' or plasma glucose }>125 \mathrm{mg} / \mathrm{dl} \text { or } \\
\text { servations - smoking status: } \mathrm{n}=52,598 \text {; pack years for current }\end{array} \quad \begin{array}{c}{ }^{2} \text { Clinicians rating 'definite' or blood pressure } \geq 140 / 90 \mathrm{~mm} \text { Hg } \\
\text { smokers: } \mathrm{n}=13,190 ; \text { BMI: } \mathrm{n}=54,939 ; \text { depression: } \mathrm{n}=51,206 \text {; men- } \\
\text { tal disability days: } \mathrm{n}=47,459 \text {; physical disability days: } \mathrm{n}=46,882 .\end{array}{ }^{3} \text { Disability days in last } 4 \text { weeks. }\end{array}$} \\
\hline
\end{tabular}

man rank correlation $(\mathrm{p}=0.10)$ with regard to their possible impact on health status. Of those variables that proved significant in bivariate analysis, reasonable variables were chosen for multiple linear regression with EQ VAS and EQ-5D index scores as dependent variables. We used a stepwise forward mode to include independent predictors with a significance level of $\alpha=0.05$. Multivariate logistic regression was applied to test for a significant predictor of single dimensions of the EQ-5D index. The 5 dimension variables were dichotomized into 'having problems' or 'having not' (e.g. no problems with daily activities equals 0 , some problems or severe problems with daily activities equals 1). Standard errors and 95\% CI were estimated using the bootstrap technique to account for the skewed distribution of the EQ-5D score. Data were weighted to adjust for nonresponse, regional distribution and attrition.

\section{Results}

\section{Patient Characteristics}

A total of 55,518 patients were included in the study; 2,181 patients had suffered a MI, 783 patients were diagnosed as having had a stroke and 145 patients had suffered both. The mean age was 67.4 years ( $\mathrm{SD}=10.2$ years) for patients with MI, compared to 68.2 years ( $\mathrm{SD}=10.8$ years) for patients who had suffered a stroke, and a mean age of 70.3 years ( $\mathrm{SD}=8.4$ years) for patients who had suffered both. $59.2 \%$ of all patients were female. Amongst the patients with MI, $29.5 \%$ were females, compared to $44.0 \%$ among stroke patients and $25.9 \%$ of those who had both stroke and MI. Further patient characteristics are provided in table 1. 
Table 2. Reported problems in EQ-5D dimensions and VAS score in patients with and without MI and/or stroke

\begin{tabular}{|c|c|c|c|c|}
\hline EQ-5D dimensions & No MI or stroke & MI & Stroke & MI and stroke \\
\hline \multicolumn{5}{|l|}{ Mobility } \\
\hline No problems $(0)$ & $35,292(73.2)$ & $1,012(51.9)$ & $278(41.3)$ & $44(34.4)$ \\
\hline Some/moderate problems (1) & $12,836(26.6)$ & $928(48.1)$ & $390(58.0)$ & $73(63.3)$ \\
\hline Extreme problems (2) & $54(0.1)$ & $0(0.0)$ & $4(0.6)$ & $3(2.4)$ \\
\hline Any problems $(1+2)$ & $12,890(26.8)$ & $928(48.1)$ & $394(58.7)$ & $76(65.6)$ \\
\hline \multicolumn{5}{|l|}{ Self-care } \\
\hline No problems $(0)$ & $44,917(92.3)$ & $1,573(80.6)$ & $462(68.7)$ & $74(58.2)$ \\
\hline Some/moderate problems (1) & $3,392(7.1)$ & $348(18.0)$ & $197(28.0)$ & $35(29.9)$ \\
\hline Extreme problems (2) & $282(0.6)$ & $28(1.4)$ & $22(3.3)$ & $11(12.0)$ \\
\hline Any problems $(1+2)$ & $3,674(7.7)$ & $376(19.4)$ & $219(31.3)$ & $46(41.8)$ \\
\hline \multicolumn{5}{|l|}{ Usual activities } \\
\hline No problems $(0)$ & $37,179(76.7)$ & $1,134(58.1)$ & $336(49.9)$ & $50(40.1)$ \\
\hline Some/moderate problems (1) & $10,446(21.8)$ & $737(38.3)$ & $297(43.8)$ & $57(47.4)$ \\
\hline Extreme problems (2) & $698(1.5)$ & $71(3.6)$ & $43(6.4)$ & $12(12.5)$ \\
\hline Any problems $(1+2)$ & $11,144(23.3)$ & $808(41.9)$ & $340(50.2)$ & $69(59.9)$ \\
\hline \multicolumn{5}{|l|}{ Pain/discomfort } \\
\hline No problems $(0)$ & $16,696(34.9)$ & 407 (21.1) & $137(20.7)$ & $14(11.6)$ \\
\hline Some/moderate problems (1) & $27,197(56.9)$ & $1,256(65.2)$ & $441(65.2)$ & $81(67.7)$ \\
\hline Extreme problems (2) & $3,786(8.2)$ & $252(13.7)$ & $95(14.2)$ & $23(20.7)$ \\
\hline Any problems $(1+2)$ & $30,983(65.1)$ & $1,508(78.9)$ & $536(79.3)$ & $104(88.4)$ \\
\hline \multicolumn{5}{|l|}{ Anxiety/depression } \\
\hline No problems $(0)$ & $34,116(71.5)$ & $1,328(69.1)$ & $388(59.1)$ & $69(54.6)$ \\
\hline Some/moderate problems (1) & $12,155(25.8)$ & $515(27.8)$ & $245(36.6)$ & $43(38.6)$ \\
\hline Extreme problems (2) & $1,250(2.7)$ & $58(3.1)$ & $28(4.3)$ & $7(6.8)$ \\
\hline Any problems $(1+2)$ & $13,405(28.5)$ & $573(30.9)$ & $273(40.9)$ & $50(45.4)$ \\
\hline EQ VAS score & $0.74(0.18)$ & $0.66(0.19)$ & $0.62(0.20)$ & $0.57(0.20)$ \\
\hline
\end{tabular}

Values denote numbers with percentages in parentheses unless otherwise indicated. Valid patient ratings: mobility $(\mathrm{n}=50,914)$; self-care $(n=51,341)$; usual activity $(n=51,060)$; pain/discomfort $(n=50,385)$; anxiety/depression $(n=50,202)$.

\section{Differences in $\mathrm{HrQoL}$}

Next, we evaluated EQ-5D values within these different groups. In each EQ-5D dimension, there is an increase in reported problems in patients with MI, stroke and both diseases as compared to patients without either of these diseases. In detail, the mean EQ-5D score was 0.74 in patients without stroke or MI, compared to 0.66 $(\mathrm{p}<0.001)$ in patients with MI and $0.62(\mathrm{p}<0.001)$ in patients with stroke. The EQ-5D values were significantly lower in patients having suffered both (0.57). A similar pattern was found for each of the 5 dimensions of mobility, self- care, usual activities, pain/discomfort and anxiety depression. Patients with a history of MI, stroke or both diseases reported significantly higher proportions of moderate and extreme problems compared to patients without stroke or MI. Detailed results can be found in table 2.

\section{Risk Factors for Cerebrovascular Disease and Associated HrQoL}

Table 3 provides an overview of the distribution of established risk factors for cerebrovascular disease for patients without stroke or MI, patients with stroke, MI and both diseases and the associated quality of life within each of these groups. Patients suffering from stroke and MI had the lowest quality of life across risk factor levels as compared to patients without stroke and MI $(\mathrm{p}<0.001)$ and patients with either stroke or MI. The HrQoL decreased with increasing risk factor levels in general. Patients with stroke or MI also reported lower HrQoL ( $\mathrm{p}<$ $0.001)$ in contrast to patients without both diseases.

\section{Multivariate Analysis to Evaluate the Association of \\ Quality of Life with Risk Factor}

Based on clinical experience we selected several risk factors known to influence HrQoL. These included age, sex, sexual dysfunction, carotid artery stenosis, BMI, anxiety/ 


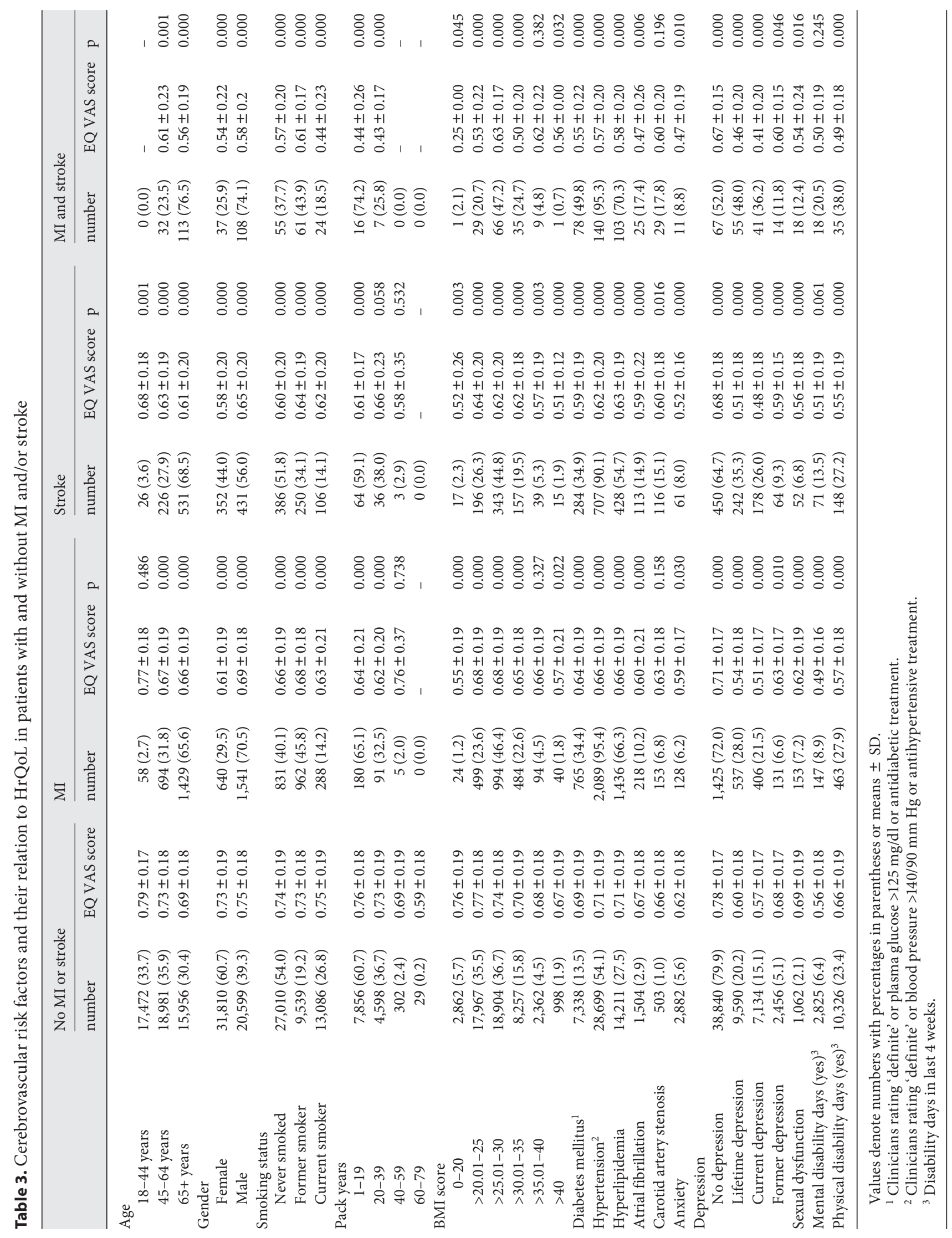


panic attacks, diabetes mellitus, depression, smoking status, blood pressure, hypercholesterinemia and atrial fibrillation. The association between risk factors and HrQoL was studied for patients without stroke or MI, and patients with stroke, MI and both diseases. The resulting $\beta$ values for the corresponding variables are given in table 4. Depression is associated with lower HrQoL across the 4 groups. Interestingly, however, lower HrQoL is associated with an increasing BMI in patients without history of stroke and MI, whereas patients with a history of stroke and MI have higher HrQoL that increases with BMI. The onset of risk factors is significantly associated with lower quality of life in patients without stroke and MI. In patients with MI and stroke, the model was able to explain only $40 \%$ of the variability. However, the small number of patients in this group $(n=145)$ needs to be considered. For all other groups, this model only explains $26-32 \%$ of the variability.

\section{Discussion}

In this representative sample of over 55,000 primary care patients we find, consistent with previous studies in partly highly selective samples $[6,15-18]$ that (1) MI as well as stroke are associated with significantly stronger reduction in quality of life than other illnesses. (2) Beyond these confirmative findings, however, we could show that stroke in particular appears to be greatest contributor to HrQoL, revealing that any pattern of comorbidity with stroke and in particular the combination of MI and stroke is associated with significantly stronger reduction in HrQoL. This leads to our conclusion the reduction in quality of life and functioning status are largely driven by the CNS complications of stroke.

We were able to identify several risk factors that influence differences in EQ-5D outcome when comparing stroke and MI. Amongst these is depression, but also smoking and mean systolic arterial blood pressure.

These data provide further evidence that early diagnosis and treatment of cardiovascular risk factors is essential to reduce subsequent stroke in patients from the German primary care system. It is most important to underline the problems associated with continued smoking. In addition, nicotine abuse was associated with reduced scores in quality of life. The same holds true for mean systolic blood pressure, which not only is known to increase the risk of renewed insult and other events, but also has a considerable impact on HrQoL.

Quality of Life and Stroke
Furthermore, it is obvious that, in addition to treatment of associated risk factors, it is essential to consider the possibility of depression and anxiety following stroke in primary care. This might be especially difficult to determine in patients with affected language, but our data detected a considerable influence of both anxiety and depression on HrQoL. It needs to be noticed that for patients with aphasia there is a specific questionnaire to be used to detect depression. Unfortunately, it was not applied in this study.

Interestingly, in our study the influence of depression is independent of MI or stroke, which indicates that depression is a problem in both diseases. It needs to be considered, however, that presence of depression directly influences HrQoL. Depression is a known independent risk factor. Therefore, early diagnosis and consequent therapy should be considered, especially during ambulatory care $[19,20]$. This may not only increase the quality of life of individual patients, but may also be important in costeffectiveness. Patients with depression are known to suffer from comorbidities that increase financial burden due to a higher number of disability days and early retirement, amongst others [21,22]. Therefore, considering and evaluating depression/anxiety in patients with MI or stroke seems important to avoid long disease duration and unnecessary complications.

Furthermore, we detected an association between HrQoL and BMI. The control group demonstrated a negative correlation between $\mathrm{BMI}$ and $\mathrm{EQ}-5 \mathrm{D}$ values, i.e. the lower the BMI status, the higher the HrQoL. In contrast, patients with MI and stroke demonstrated increasing EQ-5D values with increasing BMI scores. This association tends to change to a negative correlation by controlling for other risk conditions, but it fails statistical significance. In contrast, patients with MI or stroke demonstrated increasing EQ-5D values with increasing body weight. Currently, we do not have a data-based explanation for this finding.

Our univariate regression analysis reveals significant influences of almost all risk factors imputed. However, one needs to consider the high number of patients participating in this group. From a statistical point of view, this renders even small effects statistically significant. Looking at these data from a clinical point of view, it seems likely that at least changes in BMI group as well as presence of diabetes, hyperlipidemia and hypertension explain some of the observed variability. These are, in general, associated with negative influences on quality of life. In line with this argumentation is the observation that smoking does not significantly contribute to chang-

Cerebrovasc Dis 2011:31:68-76 
Table 4. Uni- and multivariate analyses to evaluate the association of several risk factors with HrQoL

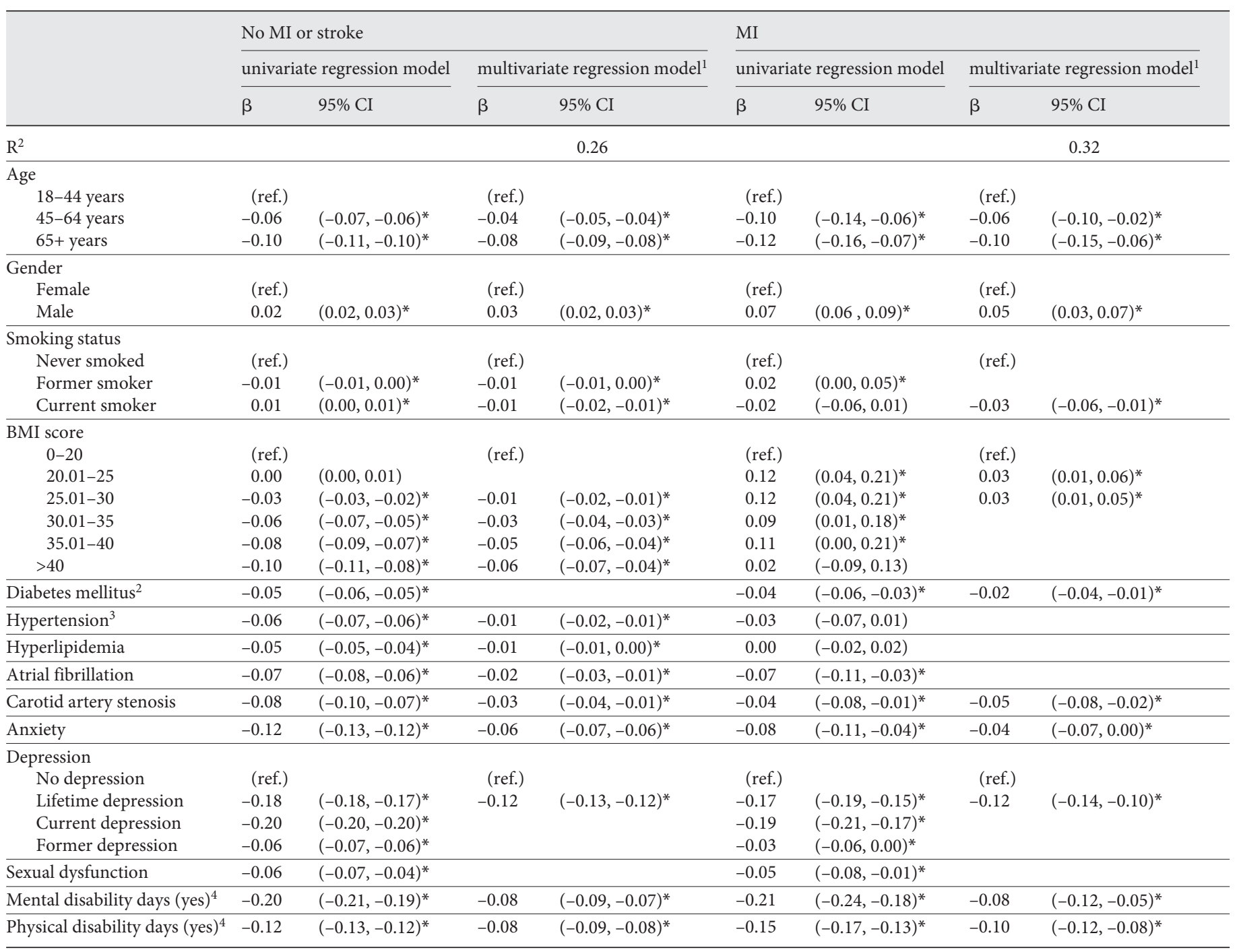

* Significant at $\mathrm{p}<0.05 .{ }^{1}$ Multivariate regression model: stepwise variable selection. ${ }^{2}$ Clinicians rating 'definite' or plasma glucose $>125 \mathrm{mg} / \mathrm{dl}$ or antidiabetic treatment. ${ }^{3}$ Clinicians rating 'definite' or blood pressure $\geq 140 / 90 \mathrm{~mm} \mathrm{Hg}$ or antihypertensive treatment. ${ }^{4}$ Disability days in last 4 weeks.

es in quality of life as there is a direct and positive influence of smoking on wellbeing.

Despite the fact that the study design was carefully chosen and a large number of patients were included in this study, there are some limitations associated with it. First, the physicians who performed the examinations of the patients did not receive a special training in how to rate them. This inevitably led to problems with scoring patients. The data quality could have been enhanced by compulsory trainings; however, the goal was to reflect the regular treatment of patients in primary care. Furthermore, no specific scores were applied to measure the severity or the disability of the neurologic deficit. Second, we only assessed the presence or absence of a disease, but there was no time scale informing us as to when a certain disease was diagnosed and how it was diagnosed according to predefined scales. Third, the study was performed in a cross-sectional design. The study sample was sufficiently large to provide a representative sample for Germany. However, patients with very severe or fatal MI or stroke were not included in this study, which may have biased its results. In addition, HrQoL was measured, but from our data it cannot directly be linked to the sequences of a given disease. It may have 


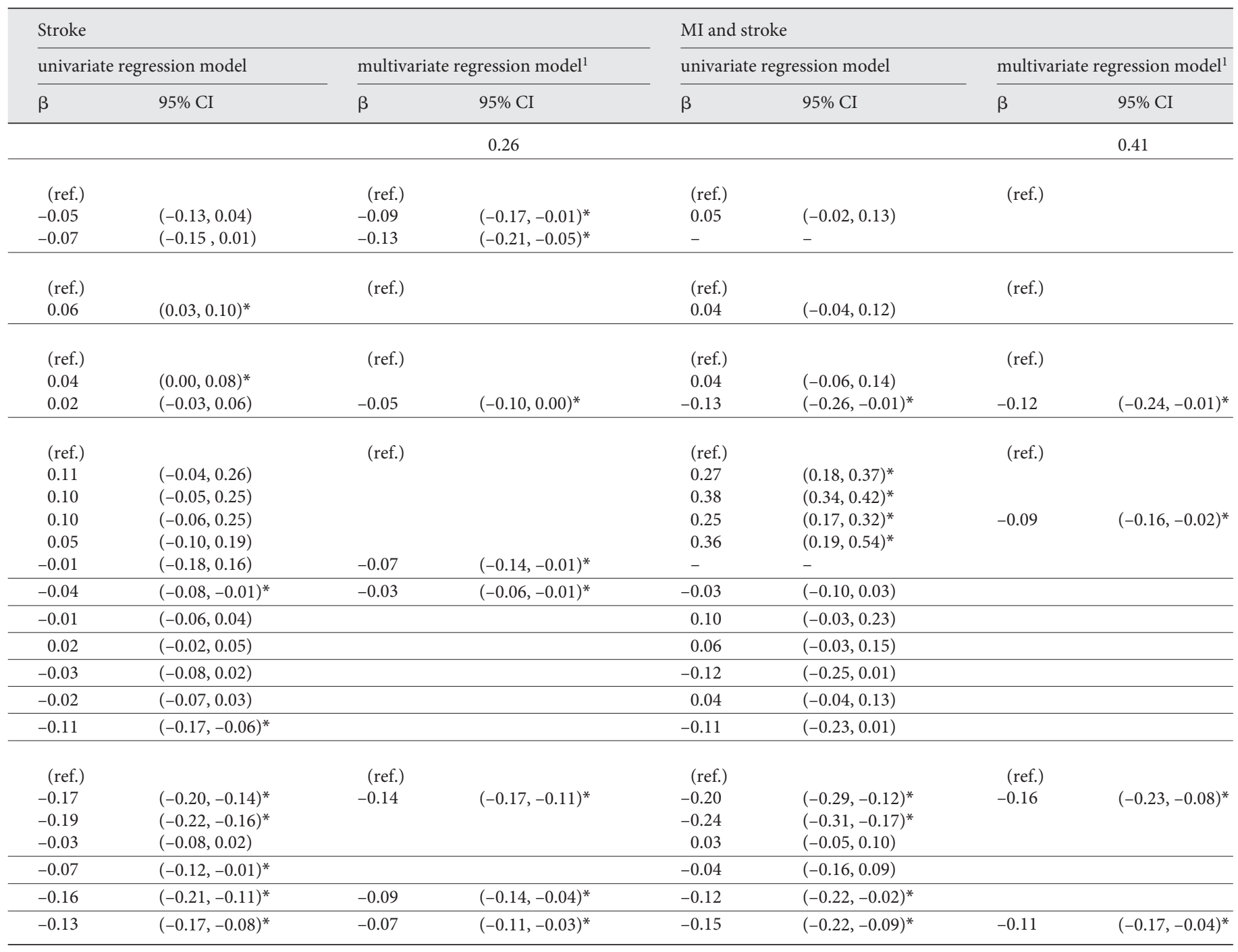

been possible that confounding variables influenced HrQoL. We tried to account for this by including the days that patients were unable to work as an indirect measure of their disability. This may serve as a possible surrogate parameter to account for the medical status related to the index diseases. Under the assumption that there is a random noise of comorbidity, this may allow one to impute quality of life to HrQoL. As can be seen from table 1 , these values are very similar across the groups. Therefore, at least the surrogate parameter demonstrates a random noise of comorbidity.

Quality of Life and Stroke
In summary, we conclude from our data that the HrQoL of patients who have had an MI and stroke is primarily determined by the CNS complications of stroke. We were able to identify several risk factors that influence differences in outcome when comparing stroke and MI.

\section{Acknowledgment}

DETECT is supported by an unrestricted educational grant from Pfizer GmbH, Karlsruhe, Germany.

Cerebrovasc Dis 2011;31:68-76 


\section{References}

1 Phillips RA: A review of therapeutic strategies for risk reduction of recurrent stroke. Prog Cardiovasc Dis 2008;50:264-273.

2 Gallego J, Martinez E, Munoz R: Patients at high risk for ischemic stroke: identification and actions. Cerebrovasc Dis 2007;24:49-63.

-3 Sacco RL: Risk factors, outcomes, and stroke subtypes for ischemic stroke. Neurology 1997;49:S39-S44.

4 Rosamond W, Flegal K, Friday G, Furie K, Go A, Greenlund K, Haase N, Ho M, Howard V, Kissela B, Kittner S, Lloyd-Jones D, McDermott M, Meigs J, Moy C, Nichol G, O’Donnell CJ, Roger V, Rumsfeld J, Sorlie P, Steinberger J, Thom T, Wasserthiel-Smoller S, Hong Y: Heart disease and stroke statistics - 2007 update: a report from the American Heart Association Statistics Committee and Stroke Statistics Subcommittee. Circulation 2007;115:e69-e171.

5 Kaplan RM, Ong M: Rationale and public health implications of changing CHD risk factor definitions. Annu Rev Public Health 2007;28:321-344.

6 Beck CA, Joseph L, Belisle P, Pilote L: Predictors of quality of life 6 months and 1 year after acute myocardial infarction. Am Heart J 2001;142:271-279.

-7 Spitzer RL, Kroenke K, Linzer M, Hahn SR, Williams JB, deGruy 3rd FV, Brody D, Davies $M$ : Health-related quality of life in primary care patients with mental disorders: results from the PRIME-MD 1000 Study. JAMA 1995;274:1511-1517.
8 EuroQol Group: EuroQol: a new facility for the measurement of health-related quality of life. Health Policy 1990;16:199-208.

$\checkmark 9$ Wittchen HU, Glaesmer H, März W, Stalla GK, Lehnert H, Zeiher AM, Silber S, Koch U, Böhler S, Pittrow D, Ruf G: Cardiovascular risk factors in primary care: methods and baseline prevalence rates - the DETECT program. Curr Med Res Opin 2005;21:619-630.

10 Pieper L, Wittchen H-U, Glaesmer H, Klotsche J, März W, Stalla GK, Lehnert H, Zeiher AM, Silber S, Koch U, Böhler S, Pittrow D, Ruf G: Kardiovaskuläre Hochrisikokonstellationen in der primärärztlichen Versorgung: DETECT Studie 2003. Bundesgesundheitsblatt Gesundheitsforschung Gesundheitsschutz 2005;12:1374-1382.

11 Pittrow D, Pieper L, Klotsche J, et al DETECT Ergebnisse einer klinisch-epidemiologischen Querschnitts- und Verlaufsstudie mit 50,000 Patienten in 3,000 Haus arztpraxen. München, Elsevier, Urban \& Fischer, 2007.

12 Wittchen H-U, Höfler M, Meister W: Prevalence and recognition of depressive syndromes in German primary care settings: poorly recognized and treated? Int Clin Psychopharmacol 2001;16:121-135.

13 Greiner W, Weijnen T, Neuwenhuizen M, Oppe S, Badia X, Busschbach J, Buxton M, Dolan P, Kind P, Krabbe P, Ohinmaa A, Parkin D, Roset M, Sintonen H, Tsuchiya A, de Charro F: A single European currency for EQ-5D health states. Eur J Health Econom 2003;4:222-231.
14 Stata Corporation: Stata statistical software, release 10.0. College Station, Stata, 2007.

$>15$ Carod-Artal FJ, Egido JA: Quality of life after stroke: the importance of a good recovery. Cerebrovasc Dis 2009;27(suppl 1):204-214.

16 Fischer U, Anca D, Arnold M, Nedeltchev K, Kappeler L, Ballinari P, Schroth G, Mattle HP: Quality of life in stroke survivors after local intra-arterial thrombolysis. Cerebrovasc Dis 2008;25:438-444.

17 Pettersen KI, Kvan E, Rollag A, Stavem K, Reikvam A: Health-related quality of life after myocardial infarction is associated with level of left ventricular ejection fraction. BMC Cardiovasc Disord 2008;8:28.

18 Xie J, Wu EQ, Zheng ZJ, Croft JB, Greenlund KJ, Mensah GA, Labarthe DR: Impact of stroke on health-related quality of life in the noninstitutionalized population in the United States. Stroke 2006;37:2567-2572.

$>19$ Leys D, Henon H, Mackowiak-Cordoliani MA, Pasquier F: Poststroke dementia. Lancet Neurol 2005;4:752-759.

20 Starkstein SE, Mizrahi R, Power BD: Antidepressant therapy in post-stroke depression. Expert Opin Pharmacother 2008;9:12911298.

21 Sobocki P, Jonsson B, Angst J, Rehnberg C: Cost of depression in Europe. J Ment Health Policy Econ 2006;9:87-98.

$>22$ Sobocki P, Lekander I, Borgström F, Ström O, Runeson B: The economic burden of depression in Sweden from 1997 to 2005. Eur Psychiatry 2007;22:146-152. 